nhánh thành phố Hồ Chí Minh, tr.418- 454

4. International Diabetes Federation (2019), "Diabetes Atlas Ninth edition 2019".

5. Bộ Y tế (2019), Hướng dẫn thực hành dược lâm sảng cho dược sĩ trong một sổ bệnh không lây nhiểm, Quyết định số 3809/QĐ-BYT, 27/08/2019, Nhà xuất bản y học, Hà Nội, tr.15-43.

6. Đào Văn Dũng (2020), P̉hương pháp nghiên cứu khoa học-Nghiên cứu hệ thống y tế, Nhà xuất bản y học, Hà Nội, tr.210-235.
7. Phạm Đình Luyến, Nguyễn Thị Hải Yến (2020), Khoa Dược-Bộ môn Quản lý dược, Kinh tế dươc, Tập 1 , Nhà xuất bản y học, Chi nhánh thành phố Hồ Chí Minh, tr.207-210.

8. Nguyê̂n Thi Kim Loan (2018) Phân tích chi phí điêu trị đái tháo đường type 2 tai bênh viên Đa khoa vạn Hạnh giai đoan 2013-2017, Luận văn Dược sĩ chuyên khoa cấp II, Trường Đại học Y Dược thành phố Hồ Chí Minh, tr.43-47, 48-70.

\title{
KẾT QUẢ PHẪU THUÂT NộI SOI ĐÎ̂̀U TRI ĐỨT DÂY CHẰNG CHÉO TRƯớC Có SỬ DỤNG VẬT LIỆU HỖ TRỢ BÊN TRONG
}

\section{TÓM TẮT}

Muc tiêu của nghiên cứu nhằm đánh giá kết quả phẫu thuật nội soi điều trị đứt dây chằng chéo trước có sử dụng vật liệu hỗ trợbên trong. Thiết kế nghiên cứu can thiệp lâm sàng không đối chứng trên 31 bệnh nhân được chẩn đoán đứt dây chằng chéo trước và được phẫu thuật nội soi điều trị bằng nepp hỗ trợ bên trong (internal brace)tại Bệnh viện Đại học Y Hà Nội và Bệnh viện Đa khoa Saint Paull, từ tháng 01/2019 đến tháng 12/2020. Kết quả cho thây tuổi trung bình là 29,87 $\pm 7,9$; tỷ số nam/nữ $=4,2$; Thời gian phẫu thuật trung bình là là $102,3 \pm 15,5$ phút, thời gian nằm viện trung bình là $6,0 \pm 1,0$ ngày.Thang điểm Lysholm trước phẫu thuật trung bình là 60,2 $\pm 3,7$.Sau phẫu thuất 6 tháng, giá trị trung bình của điểm Lysholm được cải thiện tốt $(91,2 \pm 11,7)$;tỷ lệ đạt kết quả tốt và rất tốt $(87,1 \%)$. Điểm mức độ hoạt động Tegner trung bình trước chấn thương là6,3 30,6 (dao động từ 5-7); trước phẫu thuât là $3,3 \pm 1,1$ (dao động từ 1-5). Tại thời điểm sáu tháng sau phẫu thuật, giá trị trung bình của điểm này là $5,0 \pm 1,2$ (dao động từ 27). Phẫu thuật nội soi điều trị đứt dây chằng chéo trước có sử dụng vật liệu hỗ trợ bên trong cho kết quả rất khả quan. brace

Tư khóa: dây chằng chéo trước, nội soi, internal

\section{SUMMARY \\ OUTCOME OF ARTHROSCOPIC TREATMENT ANTERIOR CRUCIATE LIAGMENT TEAR BACK UP WITH INTERNAL BRACE}

Objective of the study was to evaluate the results ofarthroscopic treatment anterior cruciate ligament tear back up with internal brace. A clinical intervention study design was applied in 31 patients diagnosed with anterior cruciate ligament tear and treated by

\footnotetext{
${ }^{1}$ Trường Đai hoc Y Hà Nôi,

${ }^{2}$ Bệnh viện Đại học Y Hà Nội

Chiu trách nhiệm chính: Đào Xuân Thành

Email: daoxuanthanh@hmu.edu.vn

Ngày nhận bài: 16.8.2021

Ngày phản biện khoa học: 15.10.2021

Ngày duyệt bài: 22.10.2021
}

Vũ Trung Hiếu ${ }^{1}$, Đào Xuân Thành ${ }^{1,2}$

arthroscopic back up with internal brace in Hanoi Medical University Hospital and Saint Paul Hospital from January 2019 to December 2020 wererecruited. Results shown that mean age was $29.87 \pm 7.9$ years, male/female ratio was 4.2. The mean time of operation was $102.3 \pm 15.5$ minutesand the average length of hospitalizationwas $6.0 \pm 1.0$ days. The average preoperative Lysholm score was $60.2 \pm 3.7$. At six months after operation, the average score improved to $91.2 \pm 11.7$. The excellent and good result was $87,1 \%$. The average Tegner Activity score before injury was $6.3 \pm 0.6$ (range from 5 to 7 ); average preoperative score was $3.3 \pm 1.1$ (range from 1 to 5 ). At six months after operation, the average value of this score was $5.0 \pm 1.2$ (range from 2 to 7 ).

Keywords: anterior crucuiate ligament, arthroscopic surgery, internal brace

\section{I. ĐĂT VẤN ĐỀ}

Đứt dây chằng chéo trước là chấn thương thường gặp vùng gối. Hiện nay điều trị đứt dây chằng chéo trước bao gồm bảo tồn và phẫu thuật. Phẫu thuật có 2 phương pháp chínhlà nội soi tái tạovà nồi soi sửa chữa. Sửa chữa dây chằng chéo trước trong trường hợp bệnh nhân đến sớm, đứt tại điểm bám lồi cầu đùi và chất lượng dây chằng còn tốt. ${ }^{1}$ Phương pháp phẫu thuật thứ hai là tái tạo dây chằng chéo trước bằng gân tự thân, đồng loại hoặc nhân tạo. Đây được xem là tiêu chuấn vàng trong điều trị đứt dây chằng hiện nay.Dù là sửa chữa hay tái tạo thì sức mạnh dây chằng mới sẽ khôngđược như ban đầu và có nguy cơ đứt lại.

Để hạn chế biến chứng trên thì gần đây có một phương pháp gia cố tăng cường sức mạnh dây chằng đó là sử dụng vật liệu hỗ trợ bên trong (Internal Brace-IB). Vật liệu này là một sợi cáp được bện bằng nhiều sợi tổng hợp có tên là FiberTap - đã chứng minh được khả năng chiu lực rất tốt. FiberTap đóng vai trò như một "dầy đai an toàn", giới hạn mức độ giãn của mảnh ghép DCCT, giảm thiểu tối đa nguy cơ đứt lại 
sau mổ, cho phép người bệnh tập phục hồi chức năng sớm và trở lại hoạt động thể thao như trước chấn thương.

Ở Việt Nam đã có môt số bênh viên triển khai phương pháp này nhưng hiện chưa có một nghiên cứu nào đánh giá hiệu quả lâu dài sau phẫu thuật. Vì vậy đề tài được thực hiện nhằm đánh giá kết quả phẫu thuâat nội soi điều trị đứt dây chẳng chéo trước có sử dụng vật liệu hỗ trợ dây bên trong.

\section{II. ĐỐI TƯƠNGG VÀ PHƯƠNG PHÁP NGHIÊN CỨU}

2.1.Đối tượng nghiên cứu : Gồm 31 bênh nhân được chẩn đoán đứt dây chằng chéo trước và được phấu thuật nội soi điều trị bằng nẹp hỗ trợ bên trong (internal brace) tại Bệnh viện Đại học Y Hà Nội và Bệnh viện đa khoa Saint Paul, từ tháng 01/2019 đến tháng 12/2020.

\section{Tiêu chuân lứa chọn:}

+ Bệnh nhân cótổn thương dây chằng chéo trước được chẩn đoán dựa vào lâm sàng và trên chẩn đoán hình ảnh MRI và được phẫu thuật nội soi điều trị có sử dụng vật liệu hỗ trợ bên trong (Internal brace).

+ Bệnh nhân đồng ý tham gia nghiên cứu.

+ Hồ sơ bệnh án đầy đủ.

\section{Tiêu chuẩn loai trừ:}

+ Bệnh nhân khổng đồng ý tham gia nghiên cứu.

+ Hồ sơ bệnh án không đầy đủ.

+ Bệnh nhân có kèm theo các gãy xương ở vùng khớp gối.

+ Đút DCCT ở có kèm bênh nhân kèm theo tổn thương đa dây chằng hoặc bệnh lý thoái hoá khớp gối nặng.

+ Tổn thương DCCT cả 2 chân.

+ Gãy xương chi dưới kèm theo.

+ Các bệnh lý nội khoa có chống chỉ định phẫu thuật.

+ Bệnh nhân không đủ điều kiện theo dõi và tập PHCN sau phẫu thuật.

2.2. Phương pháp nghiên cứu. Nghiên cứu được tiến hành theo phương pháp nghiên cứu can thiệp lâm sàng không đối chứng. Thu thập những bệnh nhân thỏa mãn tiêu chuẩn lựa chọn và tiêu chuẩn loại trừ, sau đó tiến hành thu thập thông tin theo một mẫu bệnh án nghiên cứu thống nhất. Cõ̃ mẫu thuận tiện, lấy vào nghiên cứu tất cả bệnh nhân đảm bảo tiêu chuẩn chọn mẫu. Bệnh nhân được thăm khám trực tiếp hoặc phỏng vấn qua điện thoại

\subsection{Xừ lý số liệu}

Số liệu được thu thập và xử lý trên phần mềm SPSS 20.0. Các biến liển tục được trình bày dưới dạng trung bình. So sánh giữa các biến liên tục bằng kiểm định t-student. Các biến rời rạc được trình bày dưới dạng \% và so sánh kết quả các biến bằng thuật toán kiểm định khi bình phương. Sự khác biệt có ý nghĩa thống kê nếu $p<0,05$.

2.4. Đạo đức nghiên cứu. Nghiên cứu được thực hiện theo quy chế của Bộ $Y$ tế về đạo đức trong nghiên cứu y sinh hoc.

Tất cả bệnh nhân được giải thích và tự nguyện tham gia vào nghiên cứu. Các thông tin về bệnh nhân được giữ bí mật thông tin, tôn trọng quyền của bệnh nhân và gia đình người bệnh.

\section{KẾT QUẢ NGHIÊN CỨU}

Nghiên cứu tiến hành trên 31 bệnh nhân được chẩn đoán đứt dây chằng chéo trước và được phẫu thuật nội soi điều trị bằng nẹp hỗ trợ bên trong (internal brace) tại Bệnh viện Đại học Y Hà Nội và Bệnh viện đa khoa Saint Paul, từ tháng 01/2019 đến tháng 12/2020 trong đó có 6 bênh nhân được phẫu thuâtt sửa chữa và 25 bểnh nhân được phẫu thuât tái tao.

Bảng 1. Phân bố một số đặc điểm chung của nhóm nghiên cứu

\begin{tabular}{|c|c|c|}
\hline Đặc điếm & Kết quả & Tỷ lệ \% \\
\hline \multirow{2}{*}{ Giới } & Nam & 80,6 \\
\hline & Nữ & 19,4 \\
\hline \multirow{4}{*}{$\begin{array}{c}\text { Phân bố theo } \\
\text { nhóm tuổi }\end{array}$} & 16-20 tuối & 9,7 \\
\hline & 21-30 tuối & 48,4 \\
\hline & $31-40$ tuối & 32,1 \\
\hline & Trên 40 tuối & 9,7 \\
\hline \multirow{2}{*}{ Chân tổn thương } & Chân phải & 54,8 \\
\hline & Chân trái & 45,2 \\
\hline \multirow{3}{*}{$\begin{array}{l}\text { Nguyên nhân } \\
\text { chấn thương }\end{array}$} & Tai nạn thế thao & 74,2 \\
\hline & Tai nạn sinh hoạt & 6,5 \\
\hline & Tai nan giao thông & 19,3 \\
\hline \multirow{4}{*}{$\begin{array}{l}\text { Hình ảnh cộng } \\
\text { hưởng tứ } \\
\text { khớp gối }\end{array}$} & $\begin{array}{l}\text { Đứt hoàn toàn } \\
\text { điểm bám lồi câuu }\end{array}$ & 54,8 \\
\hline & $\begin{array}{l}\text { Đứt hoàn toàn } \\
\text { tai thân }\end{array}$ & 9,7 \\
\hline & Tiêu hoàn toàn & $29 \%$ \\
\hline & Đứt bán phần & $6,5 \%$ \\
\hline $\begin{array}{l}\text { Thời gian phâu } \\
\text { thuật trung bình }\end{array}$ & \multicolumn{2}{|c|}{$102,3 \pm 15,5$ phút } \\
\hline $\begin{array}{l}\text { Thời điếm bị tai } \\
\text { nạn trung bình }\end{array}$ & \multicolumn{2}{|c|}{$5,71 \pm 10,8$ tháng } \\
\hline
\end{tabular}

Nhận xét: Đứt dây chằng chéo trước hay gặp ở bệnh nhân nam giới trẻ tuổi và chơi thể thao.

Bảng 2. Biên độ vận động khớp gối sau phẫu thuật 6 tháng

\begin{tabular}{|c|c|c|c|c|}
\hline Biên độ & \multicolumn{2}{|c|}{ viận độ̂ gấp } & \multicolumn{2}{c|}{ Biên độ duối } \\
\cline { 2 - 5 } động & $\begin{array}{c}\text { Sốn } \\
\text { lượng }\end{array}$ & $\begin{array}{c}\text { Tỹ lệ } \\
\text { \% }\end{array}$ & $\begin{array}{c}\text { Số } \\
\text { lượng }\end{array}$ & $\begin{array}{c}\text { Tỹ lệ } \\
\text { \% }\end{array}$ \\
\hline $\begin{array}{c}\text { Không } \\
\text { hạn chế }\end{array}$ & 26 & 83,9 & 27 & 87,1 \\
\hline Hạn chế & 5 & 16,1 & 4 & 12,9 \\
\hline
\end{tabular}


Nhận xét: Có 4 bệnh nhân sau phẫu thuật 6 tháng hạn chế duỗi và 5 bệnh nhân hạn chế gấp.

Bảng 3. Thay đổi chức năng khớp gôi theo thang điểm Lysholm

\begin{tabular}{|c|c|c|c|c|}
\hline \multirow{2}{*}{$\begin{array}{c}\text { Thang điểm } \\
\text { Lysholm }\end{array}$} & \multicolumn{2}{|c|}{ Trước mố } & \multicolumn{2}{|c|}{ Sau mố } \\
\hline & $\begin{array}{c}\text { Số } \\
\text { lương }\end{array}$ & $\begin{array}{c}\text { Tỷ lệ } \\
\%\end{array}$ & $\begin{array}{c}\text { Số } \\
\text { lương }\end{array}$ & $\begin{array}{c}\text { Tỷ lệ } \\
\text { \% }\end{array}$ \\
\hline Rát +ốt & 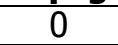 & 0 & 22 & 71 \\
\hline & 0 & 0 & $=$ & 16,1 \\
\hline & 4 & & 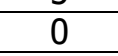 & 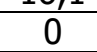 \\
\hline & 27 & 7,1 & 4 & \\
\hline
\end{tabular}

Nhận xét: Chức năng khớp gối sau mố theo thang điểm Lysholm cải thiện có ý nghĩa thống kê với $\mathrm{p}<0,05$.

Bảng 4. Đánh giá thang điểm mức độ hoạt động Tegner

\begin{tabular}{|c|c|c|}
\hline Kết quả Tegner & TB \pm SD & Min - Max \\
\hline Trước chấn thương & $6,3 \pm 0,6$ & $5-7$ \\
\hline Trước phâuu thuật & $3,3 \pm 1,1$ & $1-5$ \\
\hline Sau phâuu thuật & $5,0 \pm 1,2$ & $2-7$ \\
\hline
\end{tabular}

Nhận xét: Thang điếm mức độ hoạt động sau phẫu thuật cải thiên hơn trước phẫu thuật và giảm hơn so với trước chấn thương có ý nghĩa thống kê với $p<0,05$.

Bảng 5. Các biến chứng sau mổ

\begin{tabular}{|c|c|c|}
\hline $\begin{array}{c}\text { Biến chứng } \\
\text { sau mổ }\end{array}$ & $\begin{array}{c}\text { Số lượng bệnh } \\
\text { nhân }\end{array}$ & $\begin{array}{c}\text { Tỷ } \\
\text { lệ\% }\end{array}$ \\
\hline Nhiêm trùng & 4 & 13 \\
\hline Đứt lại & 0 & 0 \\
\hline
\end{tabular}

Nhận xét: Trong số 31 bệnh nhân được nghiên cứu có 4 bệnh nhân bị nhiễm trùng và không có bệnh nhân nào bị đứt lại.

\section{BÀN LUẬN}

Đứt dây chằng chéo trước là một chấn thương thường gặp ở nam giới trẻ tuổi hoạt động thể thao nhiều. Trong nghiên cứu của chúng tôi độ tuổi trung bình bệnh nhân là 29,87 $\pm 7,9$ trẻ tuổi nhất là 16 lớn nhất là 40 , độ tuổi hay gặp là tử 21 đến 30 tuổi chiếm 48,4\%. Tỷ lệ nam chiếm nhiều nhất $80,6 \%$ gấp 4,2 lần nữ giới. Tai nạn thể thao hay gặp chiếm $74,2 \%$. Kết quả của chúng tôi cũng tương tự tác giả Trần Hoàng Tùng ${ }^{2}$ có độ tuổi trung bình là 26,8, tỷ lệ nam chiếm $75 \%$, nguyên nhân tai nan thể thao chiếm $55,6 \%$. Thời gian từ lúc chấn thương đến lúc được phẫu thuật trung bình trong nghiên cứu của chúng tôi là $5,71 \pm 10,8$ tháng. Kết quả của chúng tôi tương tự như Trần Trung Dũng ${ }^{3}$ là 5,0 tháng, Lê Mạnh Sơnn ${ }^{4}$ là 6,0 tháng. 6 bệnh nhân trong nhóm sửa chữa thời gian phẫu thuật đều dưới 1 tháng, bênh nhân sớm nhất là 1 tuần.

Hình ảnh cộng hưởng từ trên 31 bênh nhân có 29 bệnh nhân đứt hoàn toàn dây chằng chéo trước chiếm $93,5 \%$, có 2 bệnh nhân đứt bán phần chiếm 6,5\%. 6 bệnh nhân trong nhóm phẫu thuật sửa chữa có 4 bênh nhân đứt hoàn toàn tai điểm bám lî̀i cầu và 2 bệnh nhân đứt bán phần.

Trong số 31 bệnh nhân có 4 bệnh nhân phải mổ lại do nhiếm trùng. Các bệnh nhân này là các trường hợp nội soi tái tạo dây chằng.

Tại thời điểm 6 tháng sau phẩu thuật có 4 bệnh nhân hạn chế duỗi và 5 bệnh nhân hạn chế gấp trong đó có 4 trường hợp hạn chế gấp duỗi là do bệnh nhân có biến chứng phải phải mổ lại, môt trường hợp còn lai hạ chế gấp là do sau mổ bê̂nh nhân không tập phục hồi chức năng.

Điểm Lysholm tại thời điểm sau mổ 6 tháng trung bình là $91,2 \pm 11,7$ điểm, trong đó tốt và rất tốt là $87 \%$, có 4 bệnh nhân chiếm $13 \%$ đạt kết quả xấu là những trường hợp mổ lại. Điểm Lysholm thấp nhất trong nghiên cứu chúng tôi là 58 điểm. Trường hợp này được nội soi tái tạo dây chằng chéo trước, sau mổ bệnh nhân có nhiễm trùng khớp gối và đã được phẫu thuật lại 3 lần. Điểm Lysholm trong nghiên cứu của chúng tôi cải thiện trước và sau mổ có ý nghĩa thống kê. Kết quả của một số tác giả nước ngoài có sử dụng vật liệu hố trợ bên trong như Kristian Nikolaus Schneider ${ }^{5}$ trung bình là 92,6 điểm, Harmen D. Vermeijden ${ }^{6}$ trung bình là 91,3 điểm.

Điểm mức độ hoạt động Tegner trung bình trước chấn thương là $6,3 \pm 0,6$, trước phẫu thuật là $3,3 \pm 1,1$ và sau phẫu thuật là $5,0 \pm 1,2$. Có sự khác biệt thang điểm Tegner sau phẫu thuật so với trước chấn thương và trước phẫu thuật. Tác giả RKalina ${ }^{7}$ và cộng sự nghiên cứu 46 bệnh nhân được phẫu thuật sửa chữa dây chằng chéo trước có sử dụng vật liệu hỗ trợ bên trong từ tháng 11 năm 2016 đến tháng 12 năm 2018, điểm mức độ hoạt động Tegner tại thời điểm sáu tháng sau phẫu thuật có giá trị trung bình là 7,35.

\section{KẾT LUẬN}

Qua nghiên cứu trên 31 bệnh nhân được phẫu thuật nội soi điều trị đứt dây chằng chéo trước có sử dụng vật liệu hố trợ bên trong chủ yếu là nam giới trẻ tuổi nguyên nhân tai nạn là do thể thao. Phẫu thuật nội soi điều trị đứt dây chằng chéo trước có sử dụng vật liệu hỗ trợ bên trong cho kết quả rất khả quan dựa trên thang điểm Lysholm được cải thiện hơn trước mổ,thang điểm đánh giá mức độ hoạt động Tegner sau mổ cải thiện hơn trước phẫu thuật. Cần tiếp tục nghiên cứu với cỡ mẫu lớn hơn và thời gian theo dõi dài hơn.

TÀI LIỆ THAM KHẢO

1 Edoardo Monaco et all (2021). Acute Primary 
Repair of the Anterior Cruciate Ligament With Anterolateral Ligament Augmentation.

2. Trân Hoàng Tùng (2018). Nghiên cứu ứng dụngphẫu thuật nội soi tái tạo hai bó dây chằng chéo trước sử dung gân bánh chè đồng loại. Luân án tiến sỹ trường Đại học Y Hà Nội.

3. Trân Trung Dũng (2011), Nghiên cứu sử dụng mảnh ghép đồng loại bảo quản lạnh sâu tạo hình dây chẳng chéo trưởc khớp gối qua nội soi, Luận văn tiến sỹ y hoc. Trường Đai hoc $Y$ Hà Nôi.

4. Lê Mạnh Sơn (2015), Nghiên cứu ứng dưng phẫu thuât nội soi tái tao dây chằng chéo trước hai bó bằng gân cơ bán gân và gân cơ thon tự thân. Luận ántiến sỹ, trường Đại học $Y$ Hà Nội.

5. Kristian Nikolaus Schneider et al (2020) Good to Excellent Functional Short-Term Outcome and Low Revision Rates Following Primary Anterior Cruciate Ligament Repair Using Suture Augmentation.

6. Harmen D. Vermeijden et al (2021), Reliable Internal Consistency and Adequate Validity of the Forgotten Joint Score-12 after Primary Anterior Cruciate Ligament Repair.

7. R Kalina et all (2019). InternalBrace $A C L$ Repair- First Experiences and Outcomes.

\section{ĐÁNH GIÁ KẾT QUẢ PHẪU THUÂTTHAY BÁN PHẦN KHỚP GỐI CÓ HỖ TRỢ CỦA ROBOT TẠI BÊ̂NH VIỆN BACH MAI}

\section{TÓM TẮT}

Mục tiêu: Mô tả đặ̆c điểm dịch tễ, chẩn đoán hình ảnh và kết quả phẫu thuật thay bán phân khớp gối có hỗ trợ của Robot. Phương pháp nghiên cứu: Nghiên cứu hồi cứu và thông kê mộ tả 32 bệnh nhân thoái hóa khớp gối được điêuu trị phẫu thuật thay khớp gối bán phần tại bệnh viện Bạch Mai từ tháng 3/2017 đến tháng 4/2019. Kết quả: Tỷ lệ nữ/nam là $5,4 / 1$, độ tuổi trung bình là 65 tuổi. $18,8 \%$ bệnh nhân thoái hóa khớp gối độ II và $81,2 \%$ bệnh nhân thoái hóa khớp gối độ III theo phân độ Kellgren và Lawrence. Sau phẫu thuật điểm Lysholm cải thiện có ý nghĩa thống kê giữa các nhóm tuổi, mức đô thoái hóa khớp gối và phân loại $B M I$ với $p \leq 0,05$. Kết luận: Thoái hóa khớp gối ngày càng phổ biến, bên canh thay khớp gối toàn phân thay khớp gối bán phân được phát triển cho các bênh nhân thoái hóa gối 1 khoang, cùng với sư phát triển của khoa học và công nghệ thay khớp gổi bán phần có hố trớ của Robot được phát triển và đat được nhưng kết quả tốt so với thay khớp gối bán phần truyền thống.

Tư khóa: Thay khớp gối bán phân, Robot.

\section{SUMMARY}

\section{ASSESSMENT OF SURGERY RESULTS OF ROBOTIC ASSISTED PARTIAL KNEE} REPLACEMENT AT BACH MAI HOSPITAL

Aims: Describe epidemiological, imaging features and evaluate the surgical results of Robotic assisted partial knee replacement. Patients and methods: Retrospective and descriptive study of 32 patients who were diagnosed with knee osteoarthritis and treated partial knee replacement at Bach Mai hospital from 3/2017 to 4/2019. Results: In 32 patients, the

\footnotetext{
${ }^{1}$ Trường Đại học Y Hà Nội,

${ }^{2}$ Bênh viên Bach Mai

Chịu trách nhiệm chính: Đào Xuân Thành

Email: daoxuanthanh@hmu.edu.vn

Ngày nhận bài: 17.8.2021

Ngày phản biên khoa hoc: 18.10.2021

Ngày duyệt bài: 27.10 .2021
}

Nguyễn Đình Cẩn ${ }^{1}$, Đào Xuân Thành ${ }^{1,2}$

female/male ratio was $5,4 / 1$, the mean age was 65 years. According to Kellgren and Lawrence classification,the rates of patients with grade II and grade III were $18,8 \%$ and $81,2 \%$, respectively. The Lysholm score algorithm significantly improved the age groups, the degree of knee osteoarthritis and BMI. Conclusion: Knee osteoarthritis is becoming more and more common, besides total knee replacement, partial knee replacement has been developed for patients with a single compartment knee osteoarthritis, along with the development of science and technology of joint replacement. Robotassisted partial knee replacement is developed and achieved with good results compared to traditional partial knee replacement.

Keywords: Partial knee replacement, Robot.

\section{I. ĐẶT VẤN ĐỀ}

Thoái hóa khớp gối là bệnh lý ngày càng phổ biến ở Việt Nam, trong đó tỷ lệ bệnh nhân thoái hóa khớp gối tiên phát, thoái hóa khớp sau chấn thương, thấp khớp ngày càng tăng ảnh hưởng đến sinh hoạt của người bệnh. Có nhiều phương pháp điều trị thoái hóa khớp gối như phục hồi chức năng, giảm cân, điều trị nội khoa bằng thuốc, phầu thuật nội soi làm sạch, ghép sụn... Bệnh nhân có chỉ định thay khớp gối khi các phương pháp trên thất bại. Thay khớp gối toàn phần bắt đầu được tiến hành từ nhiêu thập kỷ trước tại Việt Nam và đem lại kết quả tốt. Tuy nhiên trong trường hợp khớp gối chỉ tổn thương một trong ba khoang, các phẫu thuật viên có thể thay thế từng khoang mà không nhất thiết phải thay toàn bộ khớp gối, giảm sang chấn và đem lại sự phục hồi chức năng vận động nhanh chóng hơn cho người bệnh. Mặc dù vậy việc thay một khoang có thể gặp khó khăn về mặt kỹ thuật hơn so với thay toàn bộ khớp gối do phần khớp gối được thay phải phù hợp các phần còn lại của khớp gối cả về kích thước, vị trí... Cùng với sự 